\title{
Employees' Collaborative Use of Green Information Systems
}

\author{
Zhaojun Yang \\ Xidian University \\ zhaojunyang@xidian.edu.cn
}

\author{
Jun Sun \\ University of Texas Rio Grande Valley \\ jun.sun@utrgv.edu
}

\author{
Yali Zhang \\ Northwestern Polytechnical University \\ zhangyl@nwpu.edu.cn
}

Ying Wang

University of Texas Rio Grande Valley

ying.wang01@utrgv.edu

\begin{abstract}
Green information system (GIS) plays an important role in the sustainable development of organizations, especially for those in emerging economy that face both economic and environmental pressures. To fulfill the purpose, employees need to work together on tasks using all kinds of GIS functions such as online collaboration and remote meeting. Researchers study GIS adoption at either the organizational level or the individual level, but few examine such technology-enabled collaboration as a cross-level phenomenon. Extending the beliefaction-outcome (BAO) framework, this study investigates the motivation, effort and performance of collaborative GIS use. In particular, there are two aspects of motivation: GIS strategy as extrinsic motivation and GIS belief as intrinsic motivation, as well as two types of performance: tangible environmental performance and intangible green image. Collective GIS effort mediates the relationships between motivation and performance variables. Empirical evidence based on survey observations collected in China supports most hypothesized relationships. The findings provide helpful insights on the best practices to promote the collaborative use of GIS for corporate sustainability.
\end{abstract}

\section{Introduction}

Concerns of environment changes bring not only risks but also opportunities for organizations in terms of sustainable development. In the ecological movement, corporations in many countries are increasingly concerned about green innovation and competitive advantage [39]. In recent years, green information systems (GIS) play an increasingly important role to promote organizational reform and improve ecological efficiency. Due to both economic and environmental pressures, corporations in emerging economy are eager to enhance their sustainability with GIS implementation [33].

GIS implementation utilizes all kinds of information and communication technologies (ICT), such as environment auditing systems, automation systems, groupware, and teleconferencing, to reduce negative impacts on environment by optimizing business activities [29]29]. Compared with green information technology (GIT) that focuses more on energy saving, high efficiency and low emissions of hardware devices, GIS concerns more about organizations' operations conducive to sustainable development [20]. For optimal results, employees need to collectively use GIS functions such as online collaboration, paperless office (e.g. email, workflow, ERP), remote meeting, and green logistics to accomplish organizational tasks. Such IT-enabled collaboration is a phenomenon involving both individual behavior and organizational endeavor.

At the organizational level, researchers pay attention to corporate preparedness to adopt GIS in terms of technology readiness and maturity as well as organizational culture and resources [47][48]. As a complex organizational endeavor, GIS implementation also depends on whether there is a forward-thinking proactive strategy [57]. Besides, it is affected by the extent to which an organization's senior managers and employees believe that GIS implementation may influence its environmental performance and green image [7].

At the individual level, researchers have identified a number of antecedents to technology acceptance and adoption [19] [44] based on cognitive models such as Fishbein and Ajzen's Theory of Reasoned Action [25]. These theories are very helpful to explain why organizations implement green IS, but not so much to investigate the effects of such an endeavor. On the other hand, Melville [43] proposed the Belief-Action-Outcome (BAO) framework to examine the whole process of GIS implementation from the cultivation of belief to the actual behavior as well as the results. 
To study the cross-level phenomenon involved in the collaborative use of GIS, this study extends the BAO framework by including both organization-level and individual-level constructs and examines their relationships from the perspective of employees. Specifically, organizational strategy on GIS is included as the extrinsic motivation for employees to collectively use GIS, in addition to individual belief regarding GIS as the intrinsic motivation. In addition, environmental performance and green image are included as tangible and intangible performances respectively. GIS effort mediates the relationships among motivation and performance variables.

Based on a literature review, this study first develops a research model of hypothesized relationships. Then it describes a survey research design to collect observations from corporations that have implemented GIS. Based on the data collected, the research model can be tested. The findings are likely to provide some useful insights on the best practices regarding how organizations may enhance employees' collaborative use of GIS to fulfill its full potential.

\section{Literature Review}

In recent years, scholars have paid more and more attention to GIS implementation in organization [5] [34] [50]. A review of existing studies reveals three main aspects of research interests: 1) the driving factors of GIS implementation; 2) the relationship between GIS implementation and organizational performance; and 3) organizational strategy on GIS.

\subsection{Driving Factors of GIS Implementation}

Among the studies that examine the driving factors of GIS implementation, some focus on the external factors whereas others focus on the internal factors. In terms of the factors outside an organization, it may implement GIS under the pressure from increasingly strict environmental policies and regulations of government as well as the pressure from market environment and social public [23]. Similarly, Molla and Abareshi [46] identified the factors that push organizations to implement GIS implementation: eco-efficiency (internal economic drivers), eco-effectiveness (social and political drivers), ecological response (external economic drivers, like market demand) and eco-legitimate (institutional drivers like standards and regulations).

From inside, an organization may implement GIS in order to improve eco-efficiency and save cost. For example, Molla, Pittayachawan and Corbitt [49] found that energy efficiency and cost reduction are two important drivers for organizations to implement GIS in the United States, Australia and New Zealand. Of course, the success of a technological innovation is indispensable from a good strategy, which influences the decision-making of its implementation [52]. In the research on the adoption and use of GIS, researchers also found that the attitude and intention of individual employees play an important role [45]. Thus GIS implementation is not a pure organizational phenomenon pushed by external pressures but a collective behavior involving individual and institutional effort for the ecological goal at large.

\subsection{Outcomes of GIS Implementation}

Not many studies have addressed the outcomes of GIS implementation as it is still an emerging phenomenon, but researchers have studied the impacts of more general green innovation. Green innovation activities mainly include green technology innovation, green management innovation and green marketing innovation, which corporations may achieve through technology, product and service [58]. Researchers found that green innovation activities enhance operational and economic performances by improving the utilization of raw materials in the production process [32]. Masanet and Horvath [41] suggested that environment-protection-centered green innovation management positively affects financial, operational and environmental performances.

Similarly, a number of studies dealing with green technology outcome address the internal economic performance and external environmental performance (e.g. [6] [29]). In addition to such tangible outcomes, green innovation management activities help organizations establish a good green image, leading to competition advantage in the long run [12]. Though a wide variety of green practice studies discuss such an intangible outcome [37] [36], it has not yet received enough attention in the GIS literature. Rather than a pure technological innovation, GIS is a socio-technical phenomenon that requires the participation of employee and facilitates their collaboration (e.g. [21]), and green image is likely an outcome of such a collective human behavior.

\subsection{Organizational GIS Strategy}

Organizational GIS strategy refers to how enterprises integrate information system (IS) functionalities with production and management activities to achieve sustainability goals like environment protection and resource conservation [30] [34]. Compared with the term green IT strategy 
[38], GIS strategy has a broader scope, as IS strategy incorporates IT strategy as well as information strategy, information management strategy and change management strategy [27].

Green strategy plays a key role in green innovation for the establishment of sustainable development goals, organizational policies, and green management structures [40] [42]. Practitioners and researchers agree that the specification and execution of GIS strategy are essential to the ecology-oriented transformation for an organization [17]. Guided by such a strategy, GIS implementation is fundamental to organizational effort of sustainable development.

Compared with other higher-level factors like green culture, GIS strategy has a more direct relationship with green innovation [4]. As strategic orientation is the precursor of innovational endeavor, researchers developed green readiness index and green maturity model. For example, Erek et al. [24] proposed the balanced scorecard and six-level maturity model about green strategy. Olson [51] proposed the maturity model and analysis framework to examine how green strategy facilitates green change decision-making at the organizational level.

Meanwhile, other studies analyzed the impact of green strategy on organizational performance, and found that the former may have both direct and indirect effects on the latter. For instance, Zhang, Shen, and $\mathrm{Wu}[60]$ found that the announcement of green strategy helps housing developers gain reputation and receive favorable land prices. On the other hand, Petzer, McGibbon and Brown [54] found that green strategy leads to cost saving mainly through the implementation of GIS. Nevertheless, researchers agree that GIS strategy affects different levels of an organization, as well as the whole process of innovational endeavor.

\section{Research Model and Hypotheses}

The literature review suggests a need to systematically examine how various variables at individual and organizational levels influence the collaborative use of GIS. It is important to categorize the variables into different groups to examine the role that each play in green innovation. The collective behavior involved in such an innovation makes it appropriate to investigate the relationships among variables from the perspective of employees in terms of their perceptions of each.

\subsection{Research Model}

Though the IS researchers have a long tradition of using psychological constructs like attitude and intention to examine how individuals use information technology, there are not many studies on employees' behavior with GIS in organizational settings. One such study by Melville [43] examines GIS implementation in organizations from the perspective of individual employees with a belief-action-outcome (BAO) model. Nevertheless the gap between internal belief and overt behavior still persists for green technology users [15], and external influence plays a key role in bridging such a gap [14].

In workplaces, intrinsic motivation arises from the internal value of an effort for an individual, and extrinsic motivation arises from the external influence on an effort, whereas their effects interact with each other on employee satisfaction and performance [1]. For environment protection-related effort, intrinsic motivation is based on the belief in the value of such an effort resulting in willingness and happiness associated with it, and extrinsic motivation is based on the compliance with the institutional forces like regulations and rules [53]. For GIS implementation, the extrinsic motivation is more about an organization's guidelines and expectation regarding its collaborative use than prohibitive rules, and GIS strategy serves that purpose.

A forward-looking strategy influences and guides employee behavior in a collective manner. For the employees of an organization, its GIS strategy influences their collaborative use of GIS. Compared with such an external influence, employees have their own value systems regarding environment and sustainability, which shape their beliefs toward GIS. Thus, GIS strategy and GIS belief constitute extrinsic and intrinsic motivations for employees to use GIS. They are the main driving forces of the collective effort of GIS usage. Such GIS effort then leads to tangible and intangible performances including environmental performance and green image. The above discussions lead to a research model in Figure 1.

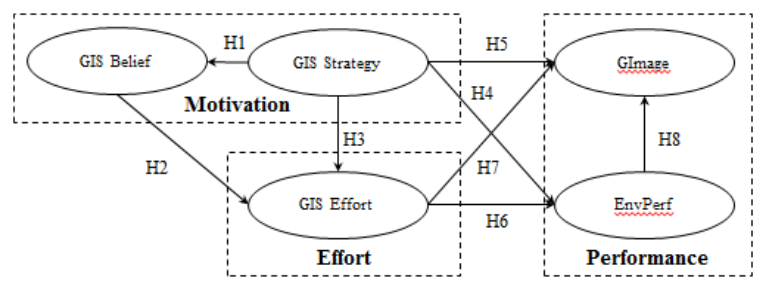

Figure 1. Research model

\subsection{Mediating Role of GIS Belief}

Generally speaking, there are three levels of strategic activities in organizations: senior managers are responsible for the overall strategy, middle-level 
managers take care of the competitive strategy, and lower-level managers are in charge of the functional strategy [8] [26]. Organizational IS strategy typically involves employees at all levels in various innovational activities, and affects their relevant belief and intention [12] [17]. Such psychological behavior is likely to lead to actual behavior with green innovation in work [44].

Establishing a GIS strategy is important to sustainable development as it leads to organizational innovation conducive to energy saving and emission reduction. A good GIS strategy gives employees clear direction and guidance regarding GIS usage, leading to their collective engagement [35]. The clearly shared strategic intent of top management team increases employees' awareness of and confidence in GIS, which are critical for their support and participation [28].

Employees' GIS-related beliefs, on the other hand, are not totally under the influence of GIS strategy but based on their own value systems, and an overall positive GIS belief is a necessary condition for an organization carry out GIS implementation [35]. Unless an organization finds most of its members ready, it may be hesitant to implement GIS despite the potential to improve environmental performance and green image [3] [16]. Thus, there is likely a partial mediation between GIS strategy and GIS effort through GIS belief.

H1. GIS strategy positively influences GIS belief.

H2. GIS belief positively influences GIS effort.

H3. GIS strategy positively influences GIS effort.

\subsection{Mediating Role of GIS Effort}

GIS implementation typically involves environmental governance, product stewardship and clean technology [43]. Employees' active utilization of GIS often leads to effective communication on corporate sustainability with stakeholders like customers and partners, leading to more prominent green image [9] [32]. Thus, GIS effort is likely to partially mediate the relationships between GIS belief and GIS performance in terms of tangible environmental performance and intangible green image.

GIS strategy responds to the pressure of environmental protection by using information technology to monitor resource utilization and improve environmental efficiency [35]. A good GIS strategy provides essential guidelines for GIS implementation to effectively reduce the environmental pollution and the consumption of energy and raw materials, satisfy the requirements of increasingly strict environment and ecological regulations, and meet the growing green demand of consumers. In addition to such direct effects, GIS strategy is also likely to have indirect effects on performance variables. This time the mediator is GIS effort, which reflects the social responsibility of an organization, and is conducive to public recognition of its green image [22]. Through the partial mediation of GIS effort, therefore, the establishment of GIS strategy enhances an organization's environmental performance and green image.

H4. GIS strategy positively influences environmental performance.

H5. GIS strategy positively influences green image.

H6. GIS effort positively influences environmental performance.

H7. GIS effort positively influences green image.

\subsection{Environmental Performance and Green Image}

Compared with green image, environmental performance is a more direct outcome of GIS implementation. It is the organizational commitment to environmental performance with lower energy consumption and less pollution that establishes a green image in the mind of the public. Thus, Gholami et al. [29] found that green image is a result of improved environmental effectiveness.

H8. Environmental performance positively influences green image.

\section{Research design}

To test the hypothesized relationships in the research model, this study collected survey observations from organizations that have implemented GIS in various industries. Known as the "world's factory", China faces the challenge and opportunity of environment protection and sustainable development. Thus, the target population comprises the employees of various companies in the largest emerging economy.

\subsection{Survey Method and Sample}

The survey questionnaire mainly contains the measures of five constructs in the research model: GIS Strategy, GIS Belief, GIS Effort, Environmental Performance, and Green Image. The target population comprises the enterprises in China, which is the world's largest developing country troubled by environmental issues. Both the private and public sectors pay close attention to sustainable 
development and ecological concerns, and most people are aware of energy saving and emission reduction.

Online and on-site survey questionnaires were sent to the contacts of 279 companies using snowball sampling. In the invitation letter, there is a filtering question on whether a GIS strategy or initiative was different managerial levels (Wilks' lambda $=0.84$, $\mathrm{p}=0.64$ ), functional departments (Wilks' lambda $=0.71$, $\mathrm{p}=0.14$ ), and organizational sizes (Wilks' lambda $=0.71, \mathrm{p}=0.65)$. Thus, there is no evidence of systematic influence from those factors on participant responses.

Table 1. Descriptive Statistics, Reliability Coefficients and Correlation Matrix

\begin{tabular}{lccccccccc}
\hline \multicolumn{1}{c}{ Construct } & Mean & S.D. & alpha & C.R. & 1 & 2 & 3 & 4 & 5 \\
\hline 1.GIS Belief & 3.81 & 0.74 & 0.86 & 0.86 & $\mathbf{0 . 7 8}$ & & & & \\
2.GIS Effort & 3.86 & 0.6 & 0.88 & 0.88 & $0.36^{* *}$ & $\mathbf{0 . 8 4}$ & & & \\
3.Environmental Performance & 3.26 & 0.95 & 0.88 & 0.88 & $0.28^{* *}$ & $0.279^{* *}$ & $\mathbf{0 . 8 1}$ & & \\
4.Green image & 3.55 & 0.77 & 0.87 & 0.88 & $0.24^{* *}$ & $0.342^{* *}$ & $0.404^{* *}$ & $\mathbf{0 . 8 0}$ & \\
5.GIS strategy & 3.33 & 0.81 & 0.83 & 0.84 & $0.43^{* *}$ & $0.338^{* *}$ & $0.391^{* *}$ & $0.408^{* *}$ & $\mathbf{0 . 7 9}$ \\
\hline
\end{tabular}

Note: $* \mathrm{a}=0.05 ; * * \mathrm{a}=0.01 ; * * * \mathrm{a}=0.001 ;$ S.D. - Standard Deviation; C.R. - Composite Reliability; On the diagonal of correlation matrix are the values of average variance extracted (AVE).

established in the organization. If not, the contact was asked to provide the contact of another organization might meet the criterion. The first item in the questionnaire let respondents select the GIS functions used in their organizations. If a contact felt someone else had a better knowledge in GIS functions and strategy, he/she was instructed to give the questionnaire to that person. Among all the contacts, about one fourth reported the absence of GIS strategy or initiative in their organizations. All the other participants disclosed in the questionnaire one or more GIS functions currently used by the employees.

Altogether, 100 organizations participated in onsite surveys $(48.1 \%)$ and 108 in on-line surveys $(51.9 \%)$, leading to a total of 208 valid responses. Among the respondents, $10.6 \%$ were at the senior management level, $25.5 \%$ were at middle level, $63 \%$ were at the operational level, and $1 \%$ was not reported. A further look indicates that $41.3 \%$ participants were in the functional departments, among which $30.3 \%$ were in the R\&D department, $13.9 \%$ in manufacturing, $13.5 \%$ in marketing and $1 \%$ was in others. In terms of organizational size, $36.5 \%$ respondents were from enterprises that had over 1000 employees, $12 \%$ between 500 and 1000, 23.6\% between 100 and 500, 27.4\% below 100, and the remaining $1 \%$ was not reported.

To assess possible response bias due to different data collection methods, a MANOVA test was conducted on the on-site and online survey samples and no statistical differences were detected (Wilks' lambda $=0.90, \mathrm{p}=0.32$ ). For on-site survey participants, their responses were typically immediate, but there was usually some delay for those in the online survey (a few hours to a few weeks). Thus, the insensitivity to response time also suggested the lack of nonresponse bias [2]. Similarly, it was found that response patterns did not vary significantly across

\subsection{Measurement}

Most of questionnaire items were adapted from validated instruments in existing studies. Items measuring GIS Belief were developed based on the conceptualization of belief related to IS innovation for sustainability by [43]. Measures of GIS effort were adapted from [18] and [29] items. Measurement of Environmental Performance came from [29] and [13] studies. Measures of Green Image were derived from [13] and [10] scales. For GIS Strategy, this study adapted the items from organizational green strategy literature [11].

Common method bias of measurement responses was assessed with Harman's one-factor test [55] [56]. A principal component analysis on all the measurement items suggest that the first principal component explained $35.41 \%$ of total variance, whereas all the principle components with Eigen value larger than 1 explained $75.23 \%$ of total variance. The first common component only accounted for less than half of the variance explained by the major principle components, indicating that common method bias was not serious.

\section{Results}

This study follows the two-step approach advocated for structural equation modeling [31]. The first step is to validate construct measurement by testing the measurement model comprising the relationships between latent variables and their observed indicators. If the measurement model is acceptable, the second step is to test the structural model in terms of the hypothesized relationships among latent variables. 


\subsection{Measurement model}

This study mainly assessed the measurement model with confirmatory factor analysis (CFA). The fit indices (CFI>0.95, RMSEA < 0.08) indicates overall model fit is acceptable (Hair et al., 2009). Furthermore, the factor loadings and factor correlations were examined to assess the construct validity regarding the relationships between latent variables and observed variables. There are two main aspects: convergent validity that requires the observed indicators of each latent construct to be internally consistent, and discriminant validity that requires the latent constructs are not highly correlated [59]. For the evaluation of convergent validity, coefficient alpha $(\alpha)$, composite reliability $(\mathrm{CR})$ and average variance extracted (AVE) were obtained and reported in Table 1 together with the correlation matrix. All the AVE values were greater than the threshold of 0.5 , and all the CR and coefficient alpha values were higher than the criterion of 0.7 , suggesting acceptable convergent validity.

To examine the discriminant validity, it is recommended to compare each squared factor correlation with the corresponding pair of AVE's to see whether the former is lower than the latter [31]. In this study, the largest squared factor correlation was lower than the smallest AVE, indicating acceptable discriminant validity.

\subsection{Structural Models}

The hypothesized relationships in the research model were tested with a nested-model approach. In order to test whether the hypothesized research model (model 2) is optimal, we included alternative model 1 and alternative model 3 as competitive models. Compared with Model 2, the path coefficient between Environmental Performance and Green Image is fixed as 0 in model 1 to test the mediated effect on Green Image through Environment Performance. Model 3 adds the paths between GIS Belief and Environmental Performance as well as Green Image. Making it a saturated model in terms of the structural relationships, the addition tests the direct effects of GIS Belief on two outcome variables, Environmental Performance and Green Image. As shown in Figures 2 through 4, all the path coefficients of model 1 and model 2 were significant, whereas model 3 had a few insignificant path coefficients. Table 2 gives the fit indices of three structural models, and the comparison also indicated that that Model 2 exhibited better goodness of fit. For example, the chi-square/df ratio in model 2 is 1.707 , which is slightly lower than that of model 1 and 3 (1.774 and 1.725, respectively). The results suggest that model 2 is better than the other two models, and the research model as hypothesized is generally valid.

Table 2. The constructs evaluation of measuring model

\begin{tabular}{llllllllllll}
\hline Model & $\chi^{2}$ & $d f$ & $p$ & $\chi 2 / d f$ & NFI & CFI & GFI & AGFI & PGFI & RMR & RMSEA \\
\hline Model 1 & 227.068 & 128 & $<0.001$ & 1.774 & 0.897 & 0.952 & 0.897 & 0.863 & 0.672 & 0.065 & 0.061 \\
Model 2 & 216.829 & 127 & $<0.001$ & 1.707 & 0.901 & 0.956 & 0.902 & 0.868 & 0.67 & 0.050 & 0.058 \\
Model 3 & 215.617 & 125 & $<0.001$ & 1.725 & 0.902 & 0.956 & 0.902 & 0.866 & 0.659 & 0.049 & 0.059 \\
\hline
\end{tabular}

The internal consistence among the indicators of each construct supports the calculation of index score by taking the average of indicator scores. Table 1 also reports the descriptive statistics of index scores in terms of mean (M) and standard deviation (SD). Generally speaking, participants were quite positive about all the constructs as their mean scores were above the neutral point of 3 , though the specific responses varied. Their responses on GIS belief and GIS effort were somewhat more positive than those on GIS performance including environmental performance and green image, suggesting a lag between behavior and consequence or a gap between expectation and reality. In addition, the mean score of GIS strategy was the second lowest, indicating that participating organizations still had a big space for improvement to enhance the specification and communication of strategic plans on GIS

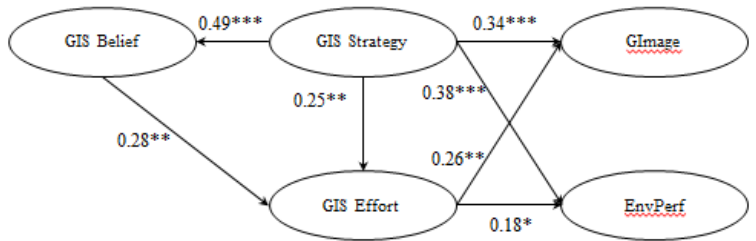

Figure 2. Alternative Model 1

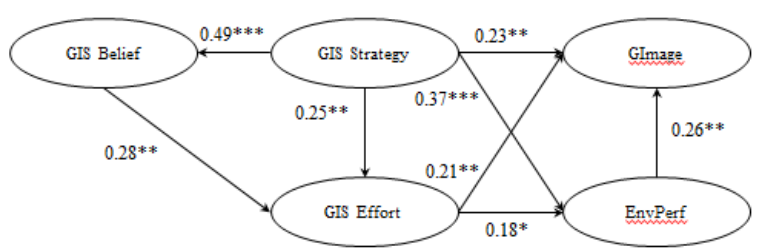

Figure 3. Model 2(hypothesized model) implementation. 


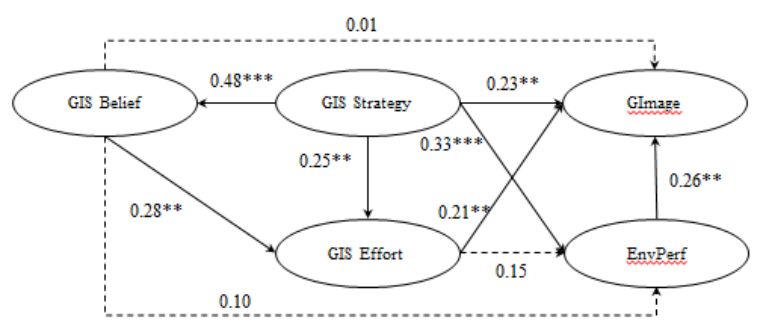

Figure 4. Alternative Model 3 (saturated model)

\subsection{Hypothesis Testing}

Figure 3 shows that GIS Strategy had significant relationships with GIS Belief, GIS Effort, Environmental Performance and Green Image. GIS Strategy not only had a direct impact on GIS Effort, but also an indirect impact through the mediation of GIS Belief (H1-H3). GIS Belief had a positive impact on GIS Effort, which mediated its effects on Environmental Performance and Green Image. Thus, GIS Effort does partially mediate the effects of GIS Strategy and GIS Belief on Environmental Performance and Green Image, as hypothesized in H4-H7. Finally, Environmental Performance had a positive impact on Green Image, supporting H8. Thus, all the hypothesized relationships in the research model were supported by the observations.

As it can be seen from the comparison of results between hypothesized research model and other two competing models, the collaborative use of GIS plays an important role in corporate sustainability. It had a positive impact not only on environmental performance (beta $=0.18, \mathrm{p}<0.05$ ) but also green image (beta $=0.21, p<0.01$ ). This suggests that GIS supports both the traditional arena of internal organizational operations and cross-organizational cooperation. The collective green effort is not just limited to employees within an organization, but shared among external suppliers and customers. The technology-facilitated joint effort undoubtedly contributes to the ecological endeavor and public reputation of an organization.

As the motivational factor at the organizational level, GIS Strategy yielded significantly positive effects on the other variables in the research model. It had the greatest impact on GIS Belief (beta $=0.49$, $p$ $<0.001)$ at the individual level. A good GIS strategy enhances employees' awareness and understanding of the initiative. The resulted positive view of GIS further affects the collaborative use of GIS (beta = $0.28, \mathrm{p}<0.01)$. In addition to such a mediating relationship, GIS strategy also had a direct effect on GIS Effort (beta $=0.25, p<0.01$ ). This suggests that GIS strategy has more than cognitive implications, but promotes the collaborative use of GIS by establishing a facilitating environment as well. As an institutional force, therefore, GIS strategy strengthened Environmental Performance (beta = $0.37, \mathrm{p}<0.001$ ) and Green Image (beta $=0.23, \mathrm{p}$ <0.01). At the same time, Environmental Performance also affected Green Image (beta $=0.26$, $\mathrm{p}<0.01)$.

\section{Conclusion and implications}

Based on a literature review, this study examines the collaborative use of GIS by extending the BAO framework with the inclusion of both individual-level and organization-level constructs. From the perspective of employees, the external influence of GIS strategy interacts with their own internal value systems regarding GIS. The collective GIS effort as motivated, in turn, has the impact on performance variables. The results support the hypothesized direct and mediated relationships involved. The findings suggest that GIS strategy as extrinsic motivation had significant direct impacts on the intrinsic motivation, effort and performance of GIS implementation, and GIS belief and GIS effort further mediate its effects on the outcome variables including environmental performance and green image.

This study has limitations, one of which is the use of single-country sample to test the hypothesized relationships. China is an emerging economy that sustainable development presents a huge challenge and opportunity for GIS implementation. Yet, other factors may also come into play in addition to environmental and economic considerations. One of such factors can be culture at the national levels. Future studies may conduct cross-culture analyses by including cultural variables and collecting observations from multiple countries and regions.

Despite the limitations, this study yields some helpful insights for researchers and practitioners. First of all, the findings suggest that GIS strategy plays an important role in the whole process of GIS implementation from motivation to performance. Without its guidance, employees' collective GIS effort may soon lose momentum or even directions. Rather, a well-established strategy helps people form a shared vision in terms of GIS belief. Once employees are mentally prepared, they are likely to participate in GIS development and utilization. The result is consistent with the previous finding regarding the relationship between GIS cognition and utilization [44]. In addition, GIS effort is found pivotal to green innovation in organizations, mediating the effects of both GIS strategy and GIS belief on environmental performance and green image. 
Compared with extant GIS research based on BAO framework [29], this study introduces GIS Strategy at the organizational level as the motivational factor on individual behavior. Moreover, this study extends the BAO framework to examine GIS implementation as a cross-level phenomenon involving technology-enabled collaboration among employees. This allows for a deeper insight of the role that organizational strategy plays in the collaborative use of GIS than most studies that treat IS strategy as largely a pure organizational phenomenon[4] [11] [24] [27]. The integration of GIS strategy and BAO framework provides a unique angle for researchers and practitioners (e.g. CIO, IT staff) to identify GIS best practices at strategic and operational levels.

For researchers, the findings provide the understanding of the relationships between strategic planning and collaborative use of GIS, in addition to the previous findings on how green innovation influences organizational performances. By taking both individual- and organization-level constructs into account, the simple linear process of GIS implementation is extended to a complex multilevel process involving a number of direct and mediated relationships. The findings contributes to the existing literature in terms of the primary driving force of GIS strategy and the mediating roles that GIS belief and GIS effort play in GIS implementation.

In the age of pursuing low carbon economy, enterprises must carry out green product innovation and sustainable management reform, by which they can create and retain competitive advantages. GIS strategy can promote enterprises to develop new business models, capture more opportunities of new markets, and achieve better long-term performances. Currently, the green innovation is still at an early stage, and many enterprises are somewhat lack of proactive planning and preparation in collective green effort. In response to competitive pressure and increasingly resource and environment problems, there is an urgent need to accelerate the green transformation, which also presents a huge opportunity for organizations. GIS strategy places the collaborative use of GIS at the core of the green innovation management to facilitate the balancing between environment and development.

This study includes both tangible environmental performance and intangible green image as outcome variables, and further examines the relationship between two. It is found that environmental performance has a significantly positive impact on green image. Organizations may build a good green image to gain a long-term competitive advantage by gradually improving the environmental performance.
On the one hand, managers may explicitly include green image in GIS strategy.

\section{Acknowledgments}

This study was funded by grants from the National Social Science Foundation of China (No. 15BGL040) and the Fundamental Research Funds for the Central Universities (No. JB160608).

\section{References}

[1] Amabile, T.M, "Motivational synergy: Toward new conceptualizations of intrinsic and extrinsic motivation in the workplace", Human Resource Management review, 3(3), 1993, pp.185-201.

[2] Armstrong, J.S., and T.S. Overton, "Estimating nonresponse bias in mail surveys", Journal of marketing research, 1977, pp.396-402.

[3] Ateş, M.A., Bloemhof, J., van Raaij, E.M., and F. Wynstra, "Proactive environmental strategy in a supply chain context: the mediating role of investments", International Journal of Production Research, 50(4), 2012, pp. 1079-1095.

[4] Bai, C., and J. Sarkis, "Green information technology strategic justification and evaluation", Information Systems Frontiers, 15(5), 2013, pp.831-847.

[5] Baumgartner, R.J., and D. Ebner, "Corporate sustainability strategies: sustainability profiles and maturity levels", Sustainable Development, 18(2), 2010, pp.76-89.

[6] Benitez-Amado, J., and R.M. Walczuch, "Information technology, the organizational capability of proactive corporate environmental strategy and firm performance: a resource-based analysis", European Journal of Information Systems, 21(6), 2012, pp.664-679.

[7] Brooks, S., Wang, X., and S. Sarker, "Unpacking Green IT: A Review of the Existing Literature", In AMCIS, 2010, August, pp. 398.

[8] Brown, S., and K. Blackmon, "Aligning manufacturing strategy and business - level competitive strategy in new competitive environments: the case for strategic resonance", Journal of Management Studies, 42(4), 2005, pp.793-815.

[9] Buysse, K., and A. Verbeke, "Proactive environmental strategies: A stakeholder management perspective", Strategic Management Journal, 24(5), 2003, pp.453-470.

[10] Chang, C.H., "The influence of corporate environmental ethics on competitive advantage: the mediation role of green innovation", Journal of Business Ethics, 104(3), 2011, pp.361-370.

[11] Chen, D.Q., Mocker, M., Preston, D.S., and A. Teubner, "Information systems strategy: reconceptualization, measurement, and implications", MIS Quarterly, 34(2), 2010, pp.233-259. 
[12] Chen, Y.S., "The driver of green innovation and green image-green core competence", Journal of business ethics, 81(3), 2008, pp.531-543.

[13] Chiou, T.Y., Chan, H.K., Lettice, F., and S.H. Chung, "The influence of greening the suppliers and green innovation on environmental performance and competitive advantage in Taiwan", Transportation Research Part E: Logistics and Transportation Review, 47(6), 2011, pp.822836.

[14] Chen, Y., Shi, S., and W.S. Chow, "Investigating Users' Extrinsic Motivation for Green Personal Computing", Journal of Computer Information Systems, 56(1), 2016, pp.70-78.

[15] Chow, W.S., and Y. Chen, "Intended belief and actual behavior in green computing in Hong Kong", Journal of Computer Information Systems, 50(2), 2009, pp.136-141.

[16] Dangelico, R.M., "Improving firm environmental performance and reputation: The role of employee green teams", Business Strategy and the Environment, 24(8), 2015, pp. 735-749.

[17] Dao, V., Langella, I., and J. Carbo, "From green to sustainability: Information Technology and an integrated sustainability framework", The Journal of Strategic Information Systems, 20(1), 2011, pp. 63-79.

[18] Daugherty, P. J., Richey, R. G., Genchev, S. E., and H. Chen, "Reverse logistics: superior performance through focused resource commitments to information technology", Transportation Research Part E: Logistics and Transportation Review, 41(2), 2005, pp.77-92.

[19] Davis, F. D., "Perceived usefulness, perceived ease of use, and user acceptance of information technology", MIS Quarterly, 13(3), 1989, pp.319-340.

[20] Dedrick, J., "Green IS: concepts and issues for information systems research", Communications of the Association for Information Systems, 27(1), 2010, pp.11-18.

[21] de Luis, M.M., Cruz, A.J.A., Arcia, A.V.U., and C.Y. Márquez, "Green Information Technology influence on car owners' behavior: Considerations for their operative support in collaborative eLearning and social networks", Computers in Human Behavior, 51, 2015, pp. 792-802.

[22] Eiadat, Y., Kelly, A., Roche, F., and H. Eyadat, "Green and competitive? An empirical test of the mediating role of environmental innovation strategy", Journal of World Business, 43(2), 2008, pp.131-145.

[23] Elliot, S., and D. Binney, "Environmentally sustainable ICT: Developing corporate capabilities and an industry-relevant IS research agenda", In PACIS, 2008, July, pp.209.

[24] Erek, K., Loeser, F., Schmidt, N.H., Zarnekow, R., and L.M. Kolbe, "Green It Strategies: A Case Study-Based Framework For Aligning Green It With Competitive Environmental Strategies”, In PACIS, 2011, July, pp.59.
[25] Fisbein, M., and I. Ajzen, "Belief, attitude, intention and behavior: an introduction to theory and research", Massachusetts, Addison-Wiley Publishing Company, 1975.

[26] Gianesi, I.G., "Implementing manufacturing strategy through strategic production planning", International Journal of Operations \& Production Management, 18(3), 1998, pp.286-299.

[27] Galliers, R.D., "Towards flexible information architecture: Integrating business strategies, information systems strategies and business process redesign", Information Systems Journal, 3(3), 1993, pp.199-213.

[28] Ghobakhloo, M., and S.H. Tang, "Information system success among manufacturing SMEs: Case of developing countries", Information Technology for Development, 21(4), 2015, pp.573-600.

[29] Gholami, R., Sulaiman, A.B., Ramayah, T., and A. Molla, "Senior managers' perception on green information systems (IS) adoption and environmental performance: Results from a field survey", Information \& Management, 50(7), 2013, pp.431-438.

[30] Goni, F.A., Sahran, S., Shukor, S.A., and A.G. Chofreh, "Aligning an information system strategy with sustainability strategy towards sustainable campus", In Research and Innovation in Information Systems (ICRIIS), 2013 International Conference, IEEE, 2013, November, pp. 245-250.

[31] Hair, J.F., Black, W.C., Babin, B.J., and R.E. Anderson, "Multivariate Data Analysis: A Global Perspective”, Upper Saddle River: Prentice Hall, 2010.

[32] Hart, S. L., and G. Dowell, "A natural-resource-based view of the firm: Fifteen years after", Journal of Management, 37(5), 2010, pp.1464-1479.

[33] Heeks, R., Subramanian, L., and C. Jones, "Understanding e-Waste Management in Developing Countries: Strategies, Determinants, and Policy Implications in the Indian ICT Sector", Information Technology for Development, 21(4), 2015, pp.653-667.

[34] Henfridsson, O., and M. Lind, "Information systems strategizing, organizational sub-communities, and the emergence of a sustainability strategy", Journal of Strategic Information Systems, 23(1), 2014, pp.11-28.

[35] Jenkin, T.A., Webster, J., and L. McShane, "An agenda for 'Green' information technology and systems research", Information and Organization, 21(1), 2011, pp.17-40.

[36] Jeong, E., Jang, S.S., Day, J., and S. Ha, "The impact of eco-friendly practices on green image and customer attitudes: An investigation in a café setting", International Journal of Hospitality Management, 41, 2014, pp.10-20.

[37] Ko, E., Hwang, Y.K., and E.Y. Kim, "Green marketing'functions in building corporate image in the retail setting", Journal of Business Research, 66(10), 2013, pp.1709-1715. 
[38] Loeser, F., Erek, K., and R. Zarnekow, "Green IT strategies: A conceptual framework for the alignment of information technology and corporate sustainability strategy", In P. O. de Pablos (ed.) Green technologies And Business Practices: An IT Approach. Information Science Reference, 2013, pp.58-95.

[39] Marchi, V.D., Maria, E.D., and S. Micelli, "Environmental strategies, upgrading and competitive advantage in global value chains", Business strategy and the environment, 22(1), 2013, pp.62-72.

[40] Mårtensson, K., and K. Westerberg, "Corporate environmental strategies towards sustainable development", Business Strategy and the Environment, 25(1), 2014, pp.19.

[41] Masanet, E., and A. Horvath, "Assessing the benefits of design for recycling for plastics in electronics: A case study of computer enclosures", Materials \& design, 28(6), 2007, pp.1801-1811.

[42] Masoumik, S.M., Abdul-Rashid, S.H., and E.U. Olugu, "Importance-performance Analysis of Green Strategy Adoption within the Malaysian Manufacturing Industry", Procedia CIRP, 26, 2015, pp.646-652.

[43] Melville, N.P., "Information systems innovation for environmental sustainability", MIS Quarterly, 34(1), 2010, pp.1-21.

[44] Mishra, D., Akman, I., and A. Mishra, "Theory of reasoned action application for green information technology acceptance", Computers in human behavior, 36, 2014, pp.29-40.

[45] Moghavvemi, S., and N. Akma Mohd Salleh, "Effect of precipitating events on information system adoption and use behavior", Journal of Enterprise Information Management, 27(5), 2014, pp.599-622.

[46] Molla, A., and A. Abareshi, "Organizational green motivations for information technology: empirical study", Journal of Computer Information Systems, 52(3), 2012, pp.92-102.

[47] Molla, A., and V. Cooper, "Green IT readiness: A framework and preliminary proof of concept", Australasian journal of information systems, 16(2), 2010, pp.5-23.

[48] Molla, A., Cooper, V., and S. Pittayachawan, "The Green IT readiness (G-Readiness) of organizations: An exploratory analysis of a construct and instrument", Communications of the Association for Information Systems, 29(1), 2011, pp.67-96.

[49] Molla, A., Pittayachawan, S., and B. Corbitt, "Green IT diffusion: an international comparison", RMIT University: Green IT Working Paper Series. 2009.

[50] Nishant, R., "Green IS and Organizational Performance: An Empirical Examination”, In PACIS, 2012, July, pp. 185 .

[51] Olson, E.G., "Creating an enterprise-level 'green' strategy", Journal of business strategy, 29(2), 2008, pp.2.
[52] Osman, E., Beltagi, I.M., and G. Hardaker, "The Impact of Leadership Orientation on Strategic Information System Planning Processes, with an Application to Libyan Organizations", Information Technology for Development, 21(4), 2013, pp.601-627.

[53] Pelletier, L.G., Tuson, K.M., Green-Demers, I., Noels, K., and A.M. Beaton, "Why are you doing things for the environment? The motivation toward the environment scale (MTES)", Journal of applied social psychology, 28(5), 1998, pp.437-468.

[54] Petzer, C., McGibbon, C., and I. Brown, "Adoption of Green IS in South Africa: an exploratory study", In Proceedings of the South African Institute of Computer Scientists and Information Technologists Conference on Knowledge, Innovation and Leadership in a Diverse, Multidisciplinary Environment. ACM. 2011, October, pp. 330-333.

[55] Podsakoff, P.M., MacKenzie, S.B., Lee, J.Y., and N.P. Podsakoff, "Common method biases in behavioral research: a critical review of the literature and recommended remedies", Journal of applied psychology, 88(5), 2003, pp.879-903.

[56] Podsakoff, P.M., MacKenzie, S.B., and N.P. Podsakoff, "Sources of method bias in social science research and recommendations on how to control it", Annual review of psychology, 63, 2012, pp.539-569.

[57] Sangle, S., "Empirical analysis of determinants of adoption of proactive environmental strategies in India", Business Strategy and the Environment, 19(1), 2010, pp.51-63.

[58] Schiederig, T., Tietze, F., and C. Herstatt, "Green innovation in technology and innovation management-an exploratory literature review", R\&D Management, 42(2), 2012, pp.180-192.

[59] Sun, J., "Assessing goodness of fit in confirmatory factor analysis", Measurement and Evaluation in Counseling and Development, 37(4), 2005, pp.240.

[60] Zhang, X., Shen, L., and Y. Wu, "Green strategy for gaining competitive advantage in housing development: a China study", Journal of Cleaner Production, 19(2), 2011, pp. 157-167. 